Journal of

Cardiology and Vascular Medicine

\title{
Association of Cytokines IL6, IL10, IL18, TNFa in Acute Coronary Syndrome
}

\section{Nagendra Boopathy Senguttuvan', Arulselvi Subramanian ${ }^{2, *}$, Garima Agarwal ${ }^{3}$, Sundeep Mishra ${ }^{4}$, V K Bahl ${ }^{5}$}

${ }^{1} \mathrm{DM}$ (Cardiology) from AIIMS, New Delhi \& Associate Professor, Department of Cardiology, Sri Ramachandra, Institute of Higher Education and Research, Chennai

${ }^{2}$ Professor, Department of Lab Medicine, JPNATC, AIIMS

${ }^{3}$ Senior Resident, Lab Medicine, JPNATC, AIIMS

${ }^{4}$ Professor, Department of Cardiology, AIIMS

${ }^{5}$ Professor \& Head, Department of Cardiology, AIIMS

${ }^{*}$ Corresponding author: Arulselvi Subramanian, Department of Lab Medicine, JPNATC, AIIMS, Tel: 9810644033, 01126731169; E-mail address: arulselvi.jpnatc@gmail.com

Received Date: July 28, 2019 Accepted Date: September 09, 2019 Published Date: September 11, 2019

Citation: Arulselvi Subramanian (2019) Association of Cytokines IL6, IL10, IL18, TNFa in Acute Coronary Syndrome. J Cardio Vasc Med 5: 1-9.

\begin{abstract}
Introduction: Cardiovascular diseases remain the leading cause of mortality and morbidity globally. A quarter of all mortality is attributable to CVD. In spite of guideline-directed treatment for patients with coronary artery diseases (CAD) that includes but not limited to the treatment of diabetes, hypertension and aggressive LDL lowering. In spite of all of this therapy, $10 \%$ of individuals had major adverse coronary events. We intended to study the role of cytokines in patients with acute coronary syndrome so as to pave a new frontier in the diagnosis and treatment of such patients.
\end{abstract}

Objectives: To determine serum cytokines levels (IL-6, IL-10, IL-18, and TNF-alpha) and their significance in patients with acute coronary syndrome (ACS).

Methods: The study population included 120 patients with acute coronary syndrome (ACS) and 60 healthy controls. These patients were divided into two groups based on electrocardiographic evidence of ST-elevation: 60 patients in Non-ST elevation MI (NSTEMI) (Group-1) and 60 patients in ST-elevation MI (STEMI) group(Group-2). Serial measurements of cytokines were done in 55 patients in group-1 and 59 in group -2. Serum levels of IL-6, IL-10, IL-18, and TNF-alpha, were measured by enzyme-linked immunosorbent assay (ELISA).

Results: Serum IL-6, IL18, and TNF-alpha were significantly higher in ACS groups (STEMI and NSTEMI) when compared to the control group. There was no significant difference in serum level of IL-10 between STEMI, NSTEMI group and controls. In both, the groups, serum level of IL-10 was significantly higher and IL-18 was significantly lower after 3 days of followup. There was no correlation between serum creatinine kinase, creatinine kinase-MB, troponin I and serum cytokine level in both ACS groups. There was no correlation found between serum levels of these cytokines and the site of MI (Anterior/ Inferior / Posterolateral).

Conclusion: Serum levels of cytokines (IL-6, IL-18 and TNF-alpha) were elevated in Indian patients with ACS as compared to healthy controls. Diagnostic and therapeutic role of such cytokines needs to be determined in future studies.

Keywords: Acute coronary syndrome; cytokines; Interleukins; TNF-alpha; inflammation. 


\section{Introduction}

Cardiovascular diseases remain the leading cause of mortality and morbidity globally [1]. A quarter of all mortality is attributable to CVD. In spite of aggressive LDL lowering, 10\% of individuals had major adverse coronary events over 2 years follow up [2]. There exists a lot of scopes to improve the care of prognosis of such patients if we understand the pathogenesis of acute coronary syndrome completely. Though it was clear that it is the macrophage that gets converted to foam cell after engulfing lipid underscoring the role of the immune system in the pathogenesis of atherosclerosis since Virchow's time [3], the primordial role of the immune system and inflammation in atherosclerosis gained its importance only for last 3 decades [4]. Role of inflammation as an active process rather a passive process was conceived only after the characterization of macrophage-derived cytokines [5]. Lots of available robust evidence confirms the involvement of inflammation not only in the process of plaque vulnerability but also in the stages of recruitment of monocytes that later become foam cells in the process of plaque formation and progression [5-7]. Hence acute coronary syndrome is an inflammatory state. Understanding the function and role of the immune system in the progression of atherosclerosis into a full-blown state acute coronary syndrome may pave a new frontier in the treatment of acute coronary syndrome. Though many western literatures are available assessing cytokines in patients with acute coronary syndrome, the same is not available from India. Hence, we intended to study the role of cytokines in the diagnosis of acute coronary syndrome and the role of such cytokines in prognosticating patients with acute coronary syndrome.

\section{Methods}

Patients aged $>18$ years admitted in the department of Cardiology were studied. Appropriate age and sex-matched healthy participants without any prior history of CAD were included as controls. We intended to study 120 patients with severe acute chest pain and suspected of acute coronary syndromes (ACS). Patients were divided into two groups Non-STEMI (Group-1) and STEMI (Group-2) of acute coronary syndrome [8]. The diagnosis was based on positive ECG changes or enzyme elevations and angiography studies. Patients with characteristic symptoms and ST elevation $\geq 2 \mathrm{~mm}$ in V1-V3 or $\geq 1 \mathrm{~mm}$ in other leads (in at least 2 continuous leads), ST depression consistent with posterior MI, new LBBB, established MI (old or recent): Q $\geq 0.04 \mathrm{~s}$ in V1-V6 or II, aVL, aV or elevation of cardiac enzymes; at least two of the above criteria needed for inclusion of STEMI into the study. The Inclusion criteria of Non-STEMI had two of the following criteria, 1. Characteristic chest pain 2. ST depression $>1 \mathrm{~mm}$ 3. T wave inversion. 4. Positive troponin. Patients with known collagen vascular disease, advanced liver disease, renal failure, malignant disease, septicemia or other infectious disease were excluded from this study. The study was approved by the institutional Ethics Committee, and each patient gave informed consent. Care of the patients was not interfered by any means of this study. Other than basic investigations that were done for the clinical management of the patients, we took two additional blood samples. The first sample collected immediately after admission from antecubital veins in supine position into silicon tubes with 1: 9 ratio, $9 \mathrm{ml}$ EDTA blood. The other samples collected in a similar manner 3 days later. Collected blood samples were immediately centrifuged at $4^{\circ} \mathrm{C}$ for 15 minutes at $3000 \mathrm{rpm}$. Divided plasma was stored at $-80{ }^{\circ} \mathrm{C}$ until assayed. Estimation of cytokines (IL 6, TNF a, IL10 and IL18 ) were done by the Enzyme-Linked Immunosorbent Assay(ELISA) method. The study was funded by Indian Council of Medical Research (ICMR)

Principle of measurement of cytokines: A $5 \mathrm{~mL}$ of venous blood was collected on day 0 and on day 3 from each patient preferably in the morning time before 8 AM. Sample was centrifuged for 10 minutes and the supernatant of the centrifuged sample was collected. Levels of IL- 6, IL-18, tumor necrosis factor-alpha (TNF-a) and IL-10 were measured in strict accordance with the instructions provided.

IL 18 was measured using Human IL 18 ELISA kit by sandwich ELISA method. The assay used two monoclonal antibodies against two different epitopes of human IL 18. In the wells coated with antihuman IL18 monoclonal antibody samples to be measured or standards were incubated. After washing, a peroxidase-conjugated anti-human IL 18 monoclonal antibody was added into the microwell and incubated. After another washing, the peroxidase substrate was mixed with the chromogen and allowed to incubate for an additional period of time. An acid solution was then added to each well to terminate the enzyme reaction and to stabilize the developed color. The optical density (OD) of each well was measured at $450 \mathrm{~nm}$ using a microplate reader. The concentration of human IL 18 was calibrated from a dose-response curve based on reference standards. Similar ELISA methods with the same principle were used for the other cytokines also. 


\section{Statistical analysis}

Data was recorded on designed proforma and managed on excel spreadsheet. Descriptive statistics for each of the parameters at various time points in the three groups were computed. One way analysis of variance / kruskal wallis test was applied to compare mean / median of various parameters in the three groups. The relationship between post-treatment changes in various cytokines as determined from peripheral blood and the treatment response was assessed using repeated measures analyses. STAT 9.0 statistical software was used for statistical analysis.

\section{Results}

One hundred and twenty patients with acute coronary syndrome were studied. They were divided into two groups. Group 1 had NSTEMI and Group 2 had STEMI (Table.1). Each group had 60 patients. In NSTEMI group (Group-1), total of 60 patients were included (11female) with mean age 55 (35-95 years). Sixty patients (16 female) in group 2 (STEMI group) with mean age of 54.5 years (26-82). 60 individuals (17 female) were included as controls. There was no statistical difference between group 1 and group 2 with regard to risk factors for coronary artery disease. Diabetes and hypertension were present in $25 \%$ and $50 \%$ of individuals respectively. Two-third of patients were in Killip $<3$ class. Anterior wall remained the leading site of infarction in $55 \%$ of the patient population. Similar to risk factors, we did not find any difference in the Killip class, BP status, troponin elevation and site of infarction between group 1 and group 2. Patients in group 1 had a significant history suggestive of alcohol consumption than group2. Similarly, patients in group 1 had elevated ESR and raised CK as compared to patients with group 2.

Table: 1. Baseline of physical, clinical and laboratory characteristics of Study participants

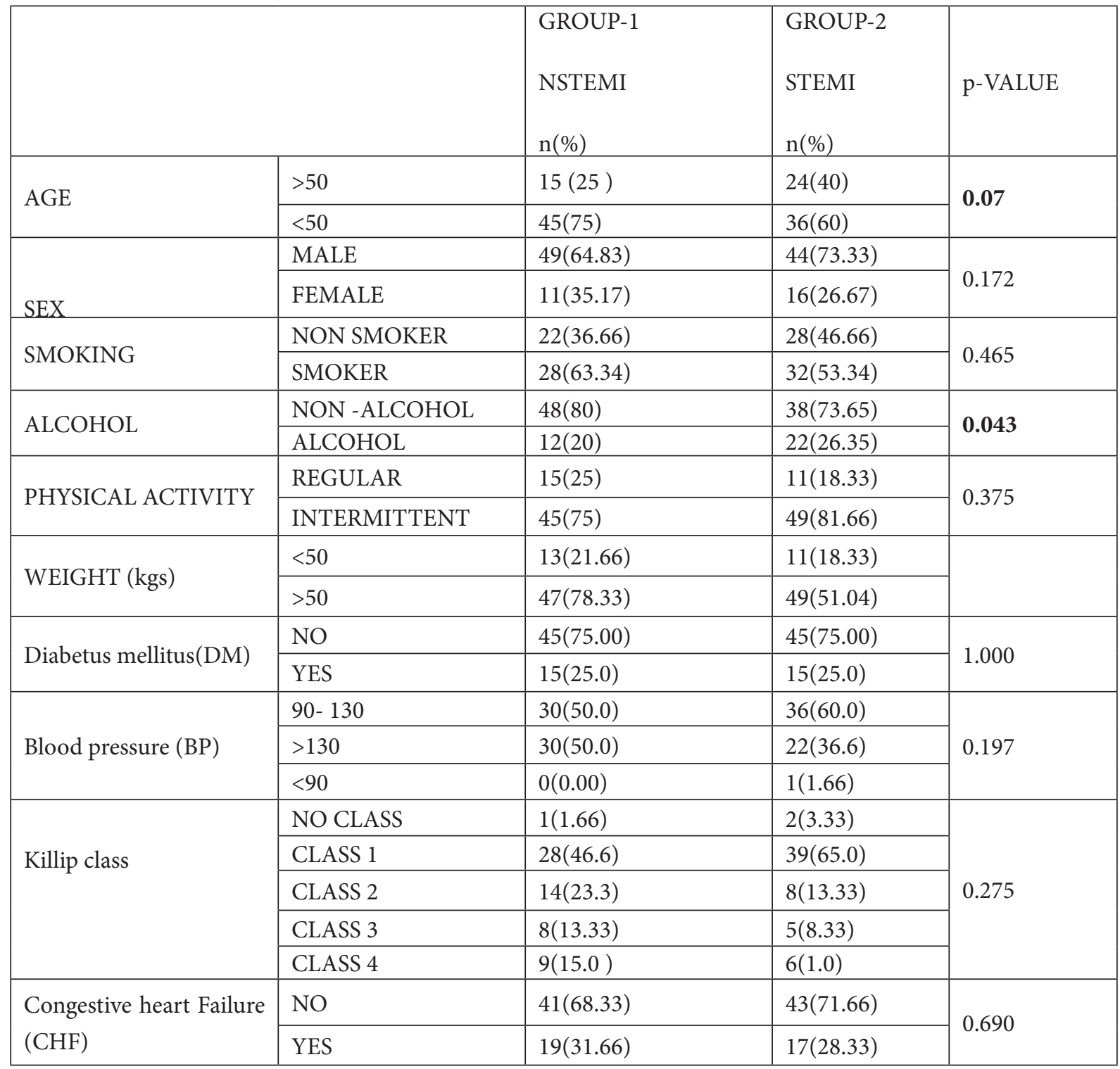




\begin{tabular}{|c|c|c|c|c|}
\hline \multirow{2}{*}{ Hemoglobin (gm/dl) } & $>9$ & $57(95.0)$ & $60(100.0)$ & \multirow{2}{*}{0.122} \\
\hline & $<9$ & $3(5.00)$ & $0(0.00)$ & \\
\hline \multirow{2}{*}{ Hematocrit (\%) } & $41-53$ & $18(30.0)$ & $22(36.66)$ & \multirow{2}{*}{0.439} \\
\hline & $1>53$ & $42(70.0)$ & $38(63.33)$ & \\
\hline \multirow{2}{*}{$\begin{array}{l}\text { Platelet count (Lakh/mi- } \\
\text { croliter) }\end{array}$} & $<1.5$ & $48(80.00)$ & $52(86.66)$ & \multirow{2}{*}{0.327} \\
\hline & $>4.5$ & $12(20.00)$ & $8(13.33)$ & \\
\hline \multirow{3}{*}{$\begin{array}{l}\text { Total leucocyte count } \\
\text { (cells/cumm) }\end{array}$} & 10000 & $48(80.0)$ & $42(70)$ & \multirow{3}{*}{0.386} \\
\hline & $>10000$ & $10(16.66)$ & $17(28.33)$ & \\
\hline & $<4000$ & $2(3.33)$ & $1(1.66)$ & \\
\hline \multirow{2}{*}{ ESR $(\mathrm{mm} / \mathrm{hr})$} & $\begin{array}{l}\text { MALE }<17, \\
\text { FEMALE }<25\end{array}$ & $16(26.66)$ & $35(58.33)$ & \multirow{2}{*}{0.000} \\
\hline & $\begin{array}{l}\text { MALE }>17, \\
\text { FEMALE }>25\end{array}$ & $44(73.33)$ & $25(41.66)$ & \\
\hline \multirow{2}{*}{ Glucose (mg/dL) } & UPTO 140 & $51(85.0)$ & $50(83.33)$ & \multirow{2}{*}{0.636} \\
\hline & $>140$ & $9(15)$ & $10(16.66)$ & \\
\hline \multirow{2}{*}{ Dyslipidemia } & $\mathrm{NO}$ & $36(60)$ & $35(58.33)$ & \multirow{2}{*}{0.853} \\
\hline & YES & $24(40)$ & $25(41.66)$ & \\
\hline \multirow{2}{*}{$\mathrm{CRP}(\mu \mathrm{g} / \mathrm{ml})$} & UPTO 3 & $28(46.66)$ & $31(51.66)$ & \multirow{2}{*}{0.584} \\
\hline & $>3$ & $32(53.33)$ & $29(48.33)$ & \\
\hline \multirow{2}{*}{ Troponin-I } & NEGATIVE & $39(65.0)$ & $34(56.66)$ & \multirow{2}{*}{0.453} \\
\hline & POSITIVE & $21(35.0)$ & $25(43.33)$ & \\
\hline \multirow{2}{*}{$\begin{array}{l}\text { Creatinine Kinase }(\mathrm{CK}) \\
(\mathrm{U} / \mathrm{L})\end{array}$} & & $43(71.66)$ & $26(43.33)$ & \multirow{2}{*}{0.002} \\
\hline & & $17(28.33)$ & $34(56.66)$ & \\
\hline \multicolumn{2}{|l|}{ Creatinine Kinase-MB (U/L) } & $8.5(0.1-267)$ & $8(0.8-414)$ & 0.637 \\
\hline \multirow{2}{*}{ Coagulopathy } & $\mathrm{NO}$ & $58(96.66)$ & $52(86.66)$ & \multirow{2}{*}{0.047} \\
\hline & YES & $2(3.33)$ & $8(13.33)$ & \\
\hline \multirow{3}{*}{ Site of infarction } & ANTERIOR & $33(55.0)$ & $33(55.00)$ & \multirow{3}{*}{1.000} \\
\hline & Coagulopathy & $26(43.33)$ & $25(41.66)$ & \\
\hline & POSTERIOR & $1(1.66)$ & $2(3.33)$ & \\
\hline
\end{tabular}

We measured TNF-alpha, IL-6, IL-10, and IL-18 on day 0 and day 3 in both groups. We intended to compare the cytokines levels measured on day 0 and day 3 amongst the participants in both groups, and also between the two groups. As compared to controls, both group 1 and group 2 had significantly elevated levels of all measured cytokines but IL-10.

In group 1(NSTEMI group), median IL-6 was 5.16ng/ $\mathrm{mL}$ (range-0-304.48) at day 0and increased to $8.26 \mathrm{ng} / \mathrm{mL}(0-$ $324.05)$ on day $3(P=\mathrm{NS})$; in addition, IL-10 increased from $1.87 \mathrm{ng} / \mathrm{mL}(0-143.05)$ at day 0 to $2.96 \mathrm{ng} / \mathrm{mL}(0-143.57)$ at day3 $(P=0.000) . I L-18$ was434.95ng/ml (23.93-4805.13) at day 0 and decreased to $123.73(0-1935.11)$ at day $3(\mathrm{P}=0.000)$. TNF-alfa was $33.48 \mathrm{ng} / \mathrm{ml}(0-98.89)$ at day 0 to $33.48(9.41-216.43)$ at day 3(P-NS) (Table.2 and Figure.1\&2). In group 2(STEMI group), median IL-6 was $1.07 \mathrm{ng} / \mathrm{ml}(0-261.87)$ at day0 increased to 1.14 $\mathrm{ng} / \mathrm{mL}(0-412.46)$ at day 3 (P-NS). IL-10 increased from the day0 value of $1.84 \mathrm{ng} / \mathrm{mL}(0-243.80)$ to $2.18 \mathrm{ng} / \mathrm{mL}(0-64.70)$ at day3 (P-NS). IL-18 decreased from 263.08(0-4872.10) at day 0 to $108.40(0-3763.62)$ at day $3(\mathrm{p}=0.002)$. TNF-alpha decreased from $60.68 \mathrm{ng} / \mathrm{ml}(0-634.43)$ to $43.53(6.61-412.46)$ at day $3(\mathrm{p}=0.008)$ (Table.2 and Figure.1\&2).

Comparison between group 1 and group 2 showed significantly lower levels of IL- 6 on day 0 and day3 in group 2 (Table. 2 and Figure.1\&2). In contrast, patients in group 2 had higher 
Table.2. Correlation of cytokines IL6, IL10, IL18 and TNF alpha among groups of STEMI, NSTEMI and controls on day 0 and day 3 of admission

\begin{tabular}{|c|c|c|c|c|c|c|c|}
\hline CYTOKINE & $\begin{array}{l}\text { GROUP 1' } \\
\text { STEMI } \\
\text { Median } \\
\text { (Min-Max) }\end{array}$ & $\begin{array}{l}\text { GROUP } 2 \\
\text { NSTEMI } \\
\text { Median } \\
\text { (Min-Max) }\end{array}$ & $\begin{array}{l}\text { GROUP } 3 \\
\text { CONTROLS } \\
\text { Median } \\
\text { (Min-Max) }\end{array}$ & $\begin{array}{l}\mathrm{P} \text {-VALUE } \\
\text { OVERALL }\end{array}$ & $1 \mathrm{VS} 2$ & $1 \mathrm{VS} 3$ & $2 \mathrm{VS} 3$ \\
\hline IL 6 -day 0 & $\begin{array}{l}5.16 \\
(0-304.48) \\
\end{array}$ & $\begin{array}{l}1.07 \\
(0-261.87)\end{array}$ & $\begin{array}{l}0.30 \\
(0-10.83)\end{array}$ & 0.0001 & 0.0026 & 0.0000 & 0.0145 \\
\hline IL 6- day 3 & $\begin{array}{l}8.26 \\
(0-324.05) \\
\end{array}$ & $\begin{array}{l}1.14 \\
(0-412.46)\end{array}$ & $\begin{array}{l}0.30 \\
(0-10.83) \\
\end{array}$ & 0.0001 & 0.0005 & 0.0000 & 0.0152 \\
\hline P VALUE & 0.123 & 0.513 & --- & --- & --- & --- & --- \\
\hline IL 10 -day 0 & $\begin{array}{l}1.87 \\
(0-143.05)\end{array}$ & $\begin{array}{l}1.84 \\
(0-243.80)\end{array}$ & $\begin{array}{l}1.42 \\
(0-189.16)\end{array}$ & 0.8157 & ---- & --- & --- \\
\hline IL10 -day 3 & $\begin{array}{l}2.96 \\
(0-143.57)\end{array}$ & $\begin{array}{l}2.18 \\
(0-64.70)\end{array}$ & $\begin{array}{l}1.42 \\
(0-189.16)\end{array}$ & 0.1032 & --- & --- & --- \\
\hline P VALUE & 0.000 & 0.485 & --- & --- & --- & --- & --- \\
\hline IL 18 -day 0 & $\begin{array}{l}434.95 \\
\left(\begin{array}{llll}2 & 3 & .93 \\
-4805.13\end{array}\right)\end{array}$ & $\begin{array}{l}263.08 \\
(0-4872.10)\end{array}$ & $\begin{array}{l}46.51 \\
(0-495.81)\end{array}$ & 0.0001 & 0.8604 & 0.0000 & 0.0000 \\
\hline IL 18- day 3 & $\begin{array}{l}123.73 \\
(0-1935.11) \\
\end{array}$ & $\begin{array}{l}108.40 \\
(0-3763.62) \\
\end{array}$ & $\begin{array}{l}46.51 \\
(0-495.81)\end{array}$ & 0.0005 & 0.1538 & 0.0025 & 0.0005 \\
\hline P VALUE & 0.000 & 0.002 & --- & --- & ---- & --- & --- \\
\hline $\begin{array}{l}\text { TNF alpha } \\
\text {-day } 0\end{array}$ & $\begin{array}{l}33.48 \\
(0-98.89)\end{array}$ & $\begin{array}{l}60.68 \\
(0-634.43)\end{array}$ & $\begin{array}{l}6.37 \\
(0-866.86)\end{array}$ & 0.0001 & 0.0000 & 0.0000 & 0.0000 \\
\hline $\begin{array}{l}\text { TNF al- } \\
\text { pha-day } 3\end{array}$ & $\begin{array}{l}33.48 \\
(9.41 \\
216.43)\end{array}$ & $\begin{array}{l}43.53(6.61- \\
412.46)\end{array}$ & $\begin{array}{l}6.37 \\
(0-866.86)\end{array}$ & 0.0001 & 0.0212 & 0.0000 & 0.0000 \\
\hline P VALUE & 0.6540 & 0.0088 & ----- & ---- & ----- & ---- & ---- \\
\hline
\end{tabular}

levels of TNF- alpha both on day 0 and day 3. No difference in IL10 and IL-18 was observed between the groups. There was no correlation found between serum levels of these cytokines and the site of MI (Anterior/ Inferior /Posterior). Other parameters which were also investigated were the relationship between the cytokine levels and creatinine kinase, creatinine kinase-MB and Troponin I levels. The influence of drug therapy thrombolyt- ics-streptokinase, glycoprotein IIa -IIIb inhibitors, and inotropic agents on levels of cytokines were also studied. Patients in Group 2 patients had an influence of drug therapy (Thrombolytics-streptokinase, Glycoprotein IIa -IIIb inhibitors, clopidogrel and Inotropics) only on the level of TNF-alfa and the difference was significant $(\mathrm{p}=0.007)$. 
Figure 1

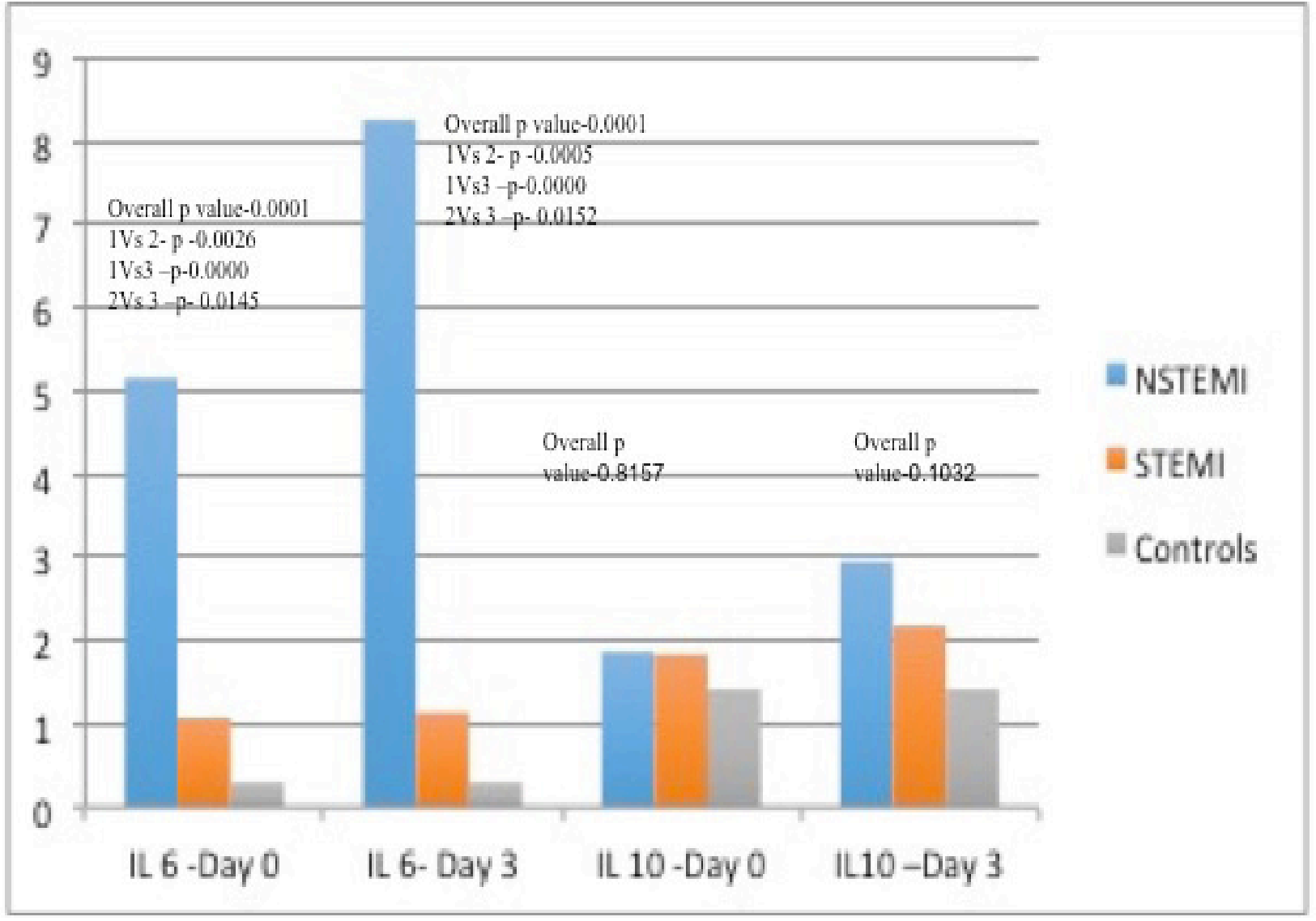

Figure 2

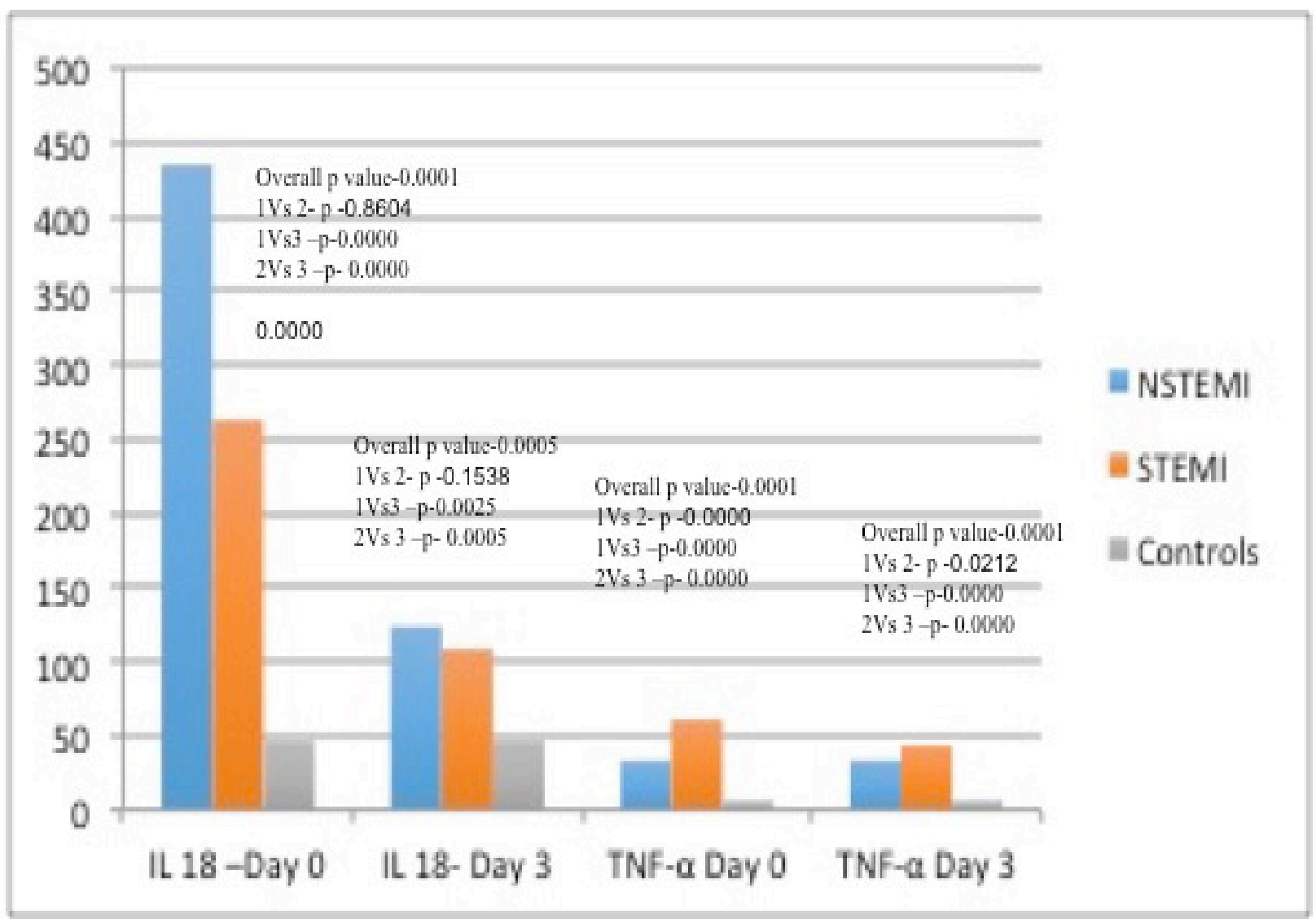




\section{Discussion}

We found significantly elevated levels of pro-inflammatory cytokines (IL-6, TNF-alpha and IL-18) in patients with acute coronary syndrome without any difference in anti-inflammatory cytokine (IL-10) level. This confirms the theory of immunoinflammatory disease in acute coronary syndrome [5]. Dominance of T-helper-1 cells was indirectly shown by elevated levels of pro-inflammatory cytokines like IL-6, IL-12and IL-18 with reduced levels of IL-10 [9]. Few studies have previously documented similar findings that inflammatory cytokines are increased in patients with ACS as compared to healthy controls [9-11]. In contrary to our findings that suggested no significant difference in the levels of IL-10 between cases and controls, Ashraf et al found increased levels of IL-10 in patients with cardiovascular diseases as compared to controls [10] while Yamashita et al found a reduced level in patients with CAD that included both patients with unstable angina and stable CAD [9]. Hence the IL10 levels may be variable in patients with the acute coronary syndrome. In addition to these studies, Chalikias et al proposed that it is the ratio of IL-18/IL-10 b [11] and not the individual levels that were found to be an independent predictor of adverse events [12]. IL - 6 has been shown to be more sensitive and specific as compared to CRP in vascular inflammation and elevated IL -6 levels correlated with increased risk of future MI. It has been proposed that IL- 6 cause plaque instability by modifying TNF-alpha and monocyte chemoattractant protein-1(MCP-1) [13] Ridker et al showed that healthy individuals with higher interleukins had a higher chance to have future MI [14]. This again supports the role of cytokines in the initial stages of atherosclerosis. They also found IL -6 to be an effective independent index of increased mortality in unstable CAD and is helpful in segregating patients who will be more benefitted by an invasive strategy. Similarly, IL6R signaling was shown to have a causal role in the pathogenesis and progression of coronary heart disease. SOLID TIMI-52 [15] study revealed that patients with elevated interleukin-6 had poor outcomes independent of other risk factors and biomarkers. They also proposed that targeting IL- 6 by novel therapeutic agents may create a paradigm shift in the management of patients with acute coronary syndrome. In CARE study; effects of elevated TNF-alpha after many months post MI were studied. They found that patients who are clinically stable but with elevated TNF-alpha levels had recurrent coronary events indicating a role of the persistence of inflammatory in stability in such patients [16].
There has been scarce data comparing biomarkers levels between Non STEMI and STEMI patients. There was no difference in the level of CRP between group 1 and group 2patients. Though plaque rupture is proposed as the major mechanism responsible for acute coronary syndrome both in STEMI and NSTEMI, the inflammatory cytokines released in these disease processes may not be the same. Among patients with ACS, patients with STEMI had significantly elevated TNF- alpha levels and reduced levels of IL-6 as compared to patients with NSTEMI. No difference in the levels of IL-10 or IL-18 was observed. Similarly, the course of serum levels of such cytokines in patients with ACS is not studied in Indian patients. The median IL-6 levels were significantly higher in the non-STEMI group as compared to the STEMI ACS group and in healthy control. Previously IL-6 has been shown to have a strong association with MACE and clinical outcomes in of patients with AHF and/or ACS. The difference in IL-6 between patients with NSTEMI and STEMI might be attributed to simultaneous multiple plaque ruptures leading to many culprit lesions that have been described more commonly in patients with NSTEMI as compared to STEMI. Similar statistically significant variations between NSTEMI and STEMI groups were not seen in IL-18 levels; There was no significant difference in serum IL 18 levels amongst Non-STEMI and STEMI patient which supports the study done by Mallat, Henry, Fressonnet et al. [11]. IL-18 decreased significantly over three days in both group 1 and group 2. Though there was no difference in the levels of IL-10 between NSTEMI and STEMI patients, patients with NSTEMI showed a significant increase in the levels of IL-10 on day 3 as compared to day0. Studies have shown that IL-10 is capable of down-regulating numerous inflammatory pathways that play an important role in the progression and stability of atherosclerotic plaque. We hypothesize that multiple simultaneous plaque rupture in such patients might have contributed to the stimulation of more requirement of anti-inflammatory cytokine involvement. TNFa levels were found to be higher in patients with STEMI as compared to NSTEMI. It decreased in STEMI patients while it did not show any change in patients with NSTEMI. This underlines the fact that patients with NSTEMI might have slow indolent ongoing inflammation as compared to patients with STEMI where anti-inflammation tries to overtake inflammatory cytokines. Previously, Heinisch et al showed persistently elevated TNF after 15 days in patients with ACS as compared to stable angina and healthy controls [17]. They also found elevated CRP and IL-6 in patients with ACS as compared to stable angina and healthy controls. Hence CAD may not be an inflammatory disease entirely but the pathogenesis of ACS revolves around inflammation. 
NSTEMI and STEMI may follow different inflammatory pathway as patients with STEMI had higher levels of TNF and lower levels of IL-6 as compared to NSTEMI. Our study supports the previous literature that IL-6, IL-18, and TNF $-\alpha$ might be used as markers in patients with acute coronary events in diagnosing them. Though it is very premature to conclude, a larger prospective study with sufficient sample size will be useful in the diagnosis and prognostication of such patients. It might also answer the finer difference between the pathogenesis between NSTEMI and STEMI.

\section{Limitations of the study}

Limitations of our study include a small sample size. We did not study coexisting or prior viral infections, unidentified autoimmune diseases and other minor infections [18] that might affect the circulating cytokines level. We studied only a few cytokines but all of them are very important as compared to others. Recently IL-37 [18] has been found to be elevated in patients with ACS with poor prognosis. We have not attempted to compare different ratios amongst the participants. Effects of drugs like statin on such inflammatory cytokines has not been assessed. High dose statin therapy has been shown to decrease the level of inflammatory cytokines [19].

\section{Conclusions}

Our results suggest that ACS is associated with significant elevation of IL-6, IL-18, and TNF-alpha. This observation indicates that different patterns of inflammatory reactions are implicated in the pathophysiology of two clinical conditions (STEMI and NON-STEMI group). Serum levels of certain cytokine might have some diagnostic value for ACS and can be a useful marker reflecting disease status.

\section{Acknowledgement}

We would like to thank ICMR for funding this study (F No 52/6/2007-BMS, RFC No BMS/20/2010-11). We would like to sincerely thank Renu Saini (SRF) and Rahul (Lab Attendant) who worked in this project.

\section{References}

1. $\mathrm{WHO} \mid$ Global Action Plan for the Prevention and Control of NCDs 2013-2020 [Internet]. [cited 2018 Dec 9].

2. Natarajan P, Jaiswal S, Kathiresan S (2018) Clonal Hematopoiesis: Somatic Mutations in Blood Cells and Atherosclerosis. Circ Genomic Precis Med11:e001926.

3. Virchow R (1858) Cellular Pathology. London: John Churchill.

4. Libby P (2012) History of Discovery: Inflammation in Atherosclerosis. Arterioscler Thromb Vasc Biol 32:2045-2051.

5. Libby P (1990) Inflammatory and immune mechanisms in atherogenesis. Vol. Vol 21. New York: Raven Press; 79-89.

6. Pant S, Deshmukh A, Gurumurthy GS, Pothineni NV, Watts TE, Romeo F, et al. (2014) Inflammation and atherosclerosis-revisited.J Cardiovasc Pharmacol Ther. 19:170-178.

7. Kavurma MM, Rayner KJ, Karunakaran D (2017) The walking dead: macrophage inflammation and death in atherosclerosis. CurrOpinLipidol. 28: 91-98.

8. Thygesen K, Alpert JS, Jaffe AS, Simoons ML, Chaitman BR, White HD, et al. (2012) Third universal definition of myocardial infarction. J Am CollCardiol 60: 1581-1598.

9. Yamashita H, Shimada K, Seki E, Mokuno H, Daida H (2003) Concentrations of interleukins, interferon, and C-reactive protein in stable and unstable angina pectoris. Am J Cardiol 91:133-136.

10. Tabrez S, Ali M, Jabir NR, Firoz CK, Ashraf GM, Hindawi S, et al. (2017) A putative association of interleukin-10 promoter polymorphisms with cardiovascular disease. IUBMB Life 69: 522-527.

11. Chalikias GK, Tziakas DN, Kaski JC, Kekes A, Hatzinikolaou EI, Stakos DA, et al. (2007) Interleukin-18/interleukin-10 ratio is an independent predictor of recurrent coronary events during a 1-year follow-up in patients with acute coronary syndrome. Int J Cardiol 117: 333-339. 
12. Mallat Z, Henry P, Fressonnet R, Alouani S, Scoazec A, Beaufils P, et al. (2002) Increased plasma concentrations of interleukin-18 in acute coronary syndromes. Heart 88:467-469.

13. Schieffer B, Schieffer E, Hilfiker-Kleiner D, Hilfiker A, Kovanen PT, Kaartinen M, et al. (2000) Expression of angiotensin II and interleukin 6 in human coronary atherosclerotic plaques: potential implications for inflammation and plaque instability. Circulation 101: 1372-1378.

14. Ridker PM, Rifai N, Stampfer MJ, Hennekens CH (2000) Plasma concentration of interleukin-6 and the risk of future myocardial infarction among apparently healthy men. Circulation 101: 1767-1772.

15. Fanola CL, Morrow DA, Cannon CP, Jarolim P, Lukas MA, Bode C, et al. (2017) Interleukin-6 and the Risk of Adverse Outcomes in Patients After an Acute Coronary Syndrome: Observations From the SOLID-TIMI 52 (Stabilization of Plaque Using Darapladib -Thrombolysis in Myocardial Infarction 52) Trial. J Am Heart Assoc. 6.

16. Ridker PM, Rifai N, Pfeffer M, Sacks F, Lepage S, Braunwald E (2000) Elevation of tumor necrosis factor-alpha and increased risk of recurrent coronary events after myocardial infarction. Circulation. 101: 2149-2153.

17. Heinisch RH, Zanetti CR, Comin F, Fernandes JL, Ramires JA, Serrano CV (2005) Serial Changes in Plasma Levels of Cytokines in Patients with Coronary Artery Disease. Vasc Health Risk Manag 1: 245-250.

18. Widen C, Holmer H, Coleman M, Tudor M, Ohlsson O, Sättlin S, et al. (2016) Systemic inflammatory impact of periodontitis on acute coronary syndrome. J Clin Periodontol 43: 713-719.

19. Liu K, Tang Q, Zhu X, Yang X (2017) IL-37 increased in patients with acute coronary syndrome and associated with a worse clinical outcome after ST-segment elevation acute myocardial infarction. Clin Chim Acta Int J Clin Chem 468: 140-144.

20. Wang K, Chen L, Liu L, Cui Y, Zhang X, Jiang J (2018) The effects of atorvastatin on IL-6, CRP, blood lipid and myocardial protection of interventional therapy in patients with acute myocardial infarction. Minerva Med.
Submit your manuscript to a JScholar journal and benefit from:

ฯ Convenient online submission

ฯ Rigorous peer review

I Immediate publication on acceptance

ๆ Open access: articles freely available online

I High visibility within the field

ब Better discount for your subsequent articles

Submit your manuscript at http://www.jscholaronline.org/submit-manuscript.php 